\title{
Examining 'Window Dressing': The Views of Black Police Associations on Recruitment and Training
}

\author{
Megan O'Neill and Simon Holdaway
}

This is a post-print version of the article which appeared as:

O'Neill, M. and Holdaway, S. (2007) 'Examining "Window Dressing”: The Views of Black Police Associations on Recruitment and Training', Journal of Ethnic and Migration Studies, 33(3): 483-500. URL:

http://www.tandfonline.com/doi/abs/10.1080/13691830701234780

In a previous issue of this journal, Ellis Cashmore (2002) discussed two key issues currently confronting police constabularies in England and Wales: the recruitment of minority ethnic officers and civilian staff, and the impact of diversity training now in place for all police officers. Cashmore argued that not only are these policies ineffective in enhancing cultural diversity within constabularies, but that they are harmful, presenting a false outward image of effective action. This article examines Cashmore's arguments and develops them in light of findings from recent research on Black Police Associations (BPA) in England and Wales. Our findings firstly suggest that, because of heavy involvement with these initiatives and the close relationship BPAs have developed with senior management (in comparison to non-BPA members), they must be considered in any discussion of minority ethnic recruitment and diversity training. In addition, the majority of the officers we interviewed were supportive of current recruitment and training programmes. Secondly, we argue that BPAs are helping to change the nature of the overall police culture to a certain extent. Many minority ethnic officers no longer feel they must downplay their ethnicity as members of constabularies.

Keywords: Black Police Associations; Minority Ethnic Recruitment; Diversity Training; Minority Ethnic Police Officers; Police Culture

In a previous paper in this journal, Ellis Cashmore (2002) discussed two key issues currently confronting police constabularies in England and Wales, namely the recruitment of minority ethnic officers and civilian staff, and the impact of diversity training ${ }^{1}$ for all police officers. On the basis of data from interviews with officers of African-Caribbean and South Asian backgrounds from three English constabularies, Cashmore argued that not only are these policies ineffective in enhancing cultural diversity within constabularies (as a way of addressing police

Megan O'Neill is Lecturer in Criminology at the University of Salford. Correspondence to: Dr M. O'Neill, School of ESPaCH, University of Salford, Crescent House, Salford, Greater Manchester M5 4WT, UK. E-mail: m.e.oneill@salford.ac.uk. Simon Holdaway is Professor of Sociology and Criminology and Director of the Centre for Criminological Research at the University of Sheffield. Correspondence to: Prof. S. Holdaway, .....??? E-mail: ???? 
racism), but that they are actually harmful, presenting a false outward image of effective action. His respondents were highly critical of both targeted minority ethnic recruitment and general police diversity training. These, they argued during interviews, were 'window dressing', and did not encourage real solutions to institutional racism. Cashmore offered his own suggestions for change (2002: 338-40), which he saw as alternatives to the current recruitment and training policies. One suggestion was to 'fast-track' minority ethnic officers into higher ranks, a technique he called 'accelerated action', in a similar way to how some officers with university degrees are currently accelerated. Cashmore argued that this would show that promotion is possible for minority ethnic officers and would increase their visibility within the workforce and the areas policed. He also suggested the development of a 'national template' of good policing practice that would chart 'instances of appropriate and helpful policing', especially those that involved minority ethnic police officers and civilians (Cashmore 2002: 339). These events would be organised and stored at a central office as a reference source for all police services nationwide, available by the police intranet. Cashmore saw these two suggestions as having the potential to be more effective in addressing the needs of minority ethnic police officers, staff and community members than targeted recruitment and diversity training.

This article re-examines Cashmore's arguments and develops them in the light of findings from our recent research on Black Police Associations (BPAs) in England and Wales. This research investigated the role and general experiences of the BPAs in their police forces. ${ }^{2}$ We conducted formal, taped interviews with the chair and deputy chair (or general secretary) of about two-thirds of the BPAs in existence at the time (a total of 33, involving visiting 23 constabularies, one of which served as a pilot). These semi-structured interviews ranged from one hour to almost three hours. We also interviewed the Assistant Chief Constable holding a personnel portfolio, the Director of Human Resources and the chair of the local Police Federation board for each force. Many topics were discussed during our interviews, such as relationships between the BPA and senior management, the history of how each BPA formed, and the challenges BPA members have faced since then. Discussions about recruitment and training came up frequently, although they were not the main focus of each interview.

The transcripts of the interviews with BPA chairs and deputy chairs/general secretaries (45 interviews in total) are the main source of our data for this paper. ${ }^{3}$ These BPA executive officers are often experts in their own right on issues of recruitment and training due to their extensive involvement in the programmes, either in executing or evaluating them. Each interviewee was assured complete confidentiality for his or her responses, and so no identifying information is given here. As there are few minority ethnic officers in senior ranks or grades, to divulge any information on rank and ethnicity would compromise confidentiality. The quotes below are clustered around specific themes and so it can be assumed that each quote in a cluster is from a different speaker. Their discussions with us were very frank and detailed, so they are quoted at length in the paper.

Our findings suggest that, because of heavy involvement with these initiatives and the close relationship BPAs have developed with senior management (in comparison to non-BPA members), they must be included in any discussion of minority ethnic recruitment and diversity training. They are the first officers senior 
management will approach on these issues and their influence and opinion cannot be ignored. In addition, these BPA chairs and deputy chairs/general secretaries' statements often contradicted the arguments Cashmore (2002) advanced. Secondly, we argue that BPAs are helping to change-to some extent-the nature of the overall police culture. Minority ethnic officers no longer feel they must downplay their ethnicity as members of constabularies. Indeed, they now identify themselves as 'black police officers', rather than 'police officers who happen to be black' (Holdaway and Barron 1997). This finding has strong implications for Cashmore's claim that increasing minority ethnic recruits will only provide more 'black faces in uniform' and is thus 'window dressing' (2002: 332).

\section{Background}

National concern with the recruitment of minority ethnic people to the police service and police diversity training can be linked back to Lord Scarman's inquiry into the Brixton riots of 1981 (Scarman 1981). Scarman wrote that there is widespread agreement that the composition of our police forces must reflect the make-up of the society they serve. In one important respect at least, it does not do so: in the police, as in other important areas of society, the ethnic minorities are very significantly under-represented' (1981: 76). In relation to training, he argued that far more time should be devoted to developing in recruits 'an understanding of the cultural backgrounds and the attitudes to be found in our ethnically diverse society' (1981: 80).

There was acceptance among senior police officers after Scarman's report was published that recruitment of minority ethnic officers did need to be addressed (Goodson 1984: 150), and some initiatives were introduced (Holdaway 1996: 139-40). However, not much had really changed in the number of minority ethnic recruits by the time of Her Majesty's Inspectorate of Constabulary (HMIC) inspection in 1993 (Holdaway 1996: 141). ${ }^{4}$ Scarman's suggestions for changes to training did not all meet with widespread acceptance from police officers (Griffiths 1984: 133), but were embraced by the Home Office, whicho set up a working party to review existing training and recommend changes (Holdaway 1996: 1234). A key aspect of the resulting recommendations was that race relations training should become a central part of a wider curriculum of community relations training.

A pilot training programme was developed and then evaluated by the Home Office Research Unit. Peter Southgate, the researcher who completed the project, found a fundamental flaw in the training: the police occupational culture. Southgate argued this was untouched by race relations training and it is said to be a continuing problem in training initiatives today (Rowe and Garland 2003). One consequence of the ascendancy of the occupational culture is that, no matter how much officers are told of the importance of the training they receive in community and race relations, they often fail to see its relevance to their daily work (Holdaway 1996: 124-5).

The next major assessment of police conduct with minority ethnic communities came with Lord Macpherson's (1999) inquiry into the police investigation of Stephen Lawrence's murder. Macpherson's recommendations set out to change police culture, viewed as a major underlying problem. This is a departure from 
Scarman who located the fault as being held jointly by the police and the community (O'Byrne 2000: 109-10). Macpherson writes:

It (institutional racism) persists because of the failure of the organisation openly and adequately to recognise and address its existence and causes by policy, example and leadership. Without recognition and action to eliminate such racism it can prevail as part of

the ethos of the culture of the organisation. It is a corrosive disease (Macpherson 1999: 28).

Like Scarman, recruitment and race relations training were part of Macpherson's plan. He noted (1999: 30) that race relations training had changed very little since the Scarman report and few gains had been made in the recruitment of minority ethnic staff (Loveday 2000: 15, 18, 24). The main significance of the Macpherson report, however, is that he recommended (and the Home Secretary accepted) the need for recruitment targets and more effective monitoring of training (O'Byrne 2000: 110-12). No longer could police forces sit back and hope the 'community' would come round to seeing them as a good place to work. Organised and deliberate action had to be taken, reported, measured and evaluated routinely.

It is now widely acknowledged among senior officers and Her Majesty's Inspectorate of Constabulary (HMIC) that the involvement of existing minority ethnic police officers and staff in recruitment and training initiatives can be beneficial. This was not always the case, however. The first BPA established in the UK was based in the Metropolitan Police. It was formed (after many years of debate and preparation) against the prior advice of senior management, who then decided to embrace it during its highly public launch in 1994 (Holdaway and O'Neill 2004). Our research has found that many of the early BPAs faced difficulties in starting their groups, but since the Macpherson Report and the launch of the National Black Police Association in 1999 (which is fully endorsed and supported by the Home Office), senior police management has been much more open to them. Not only that, but as BPAs form a key part of the HMIC 'Winning the Race' reports $(1997,1999,2001)$ and serve as an example of good practice (HMIC 2001: 74), some minority ethnic officers find themselves being approached by senior management to start up BPAs, with funding and support readily available.

BPAs are generally groups of minority ethnic police officers and civilian staff within each force who support each other, strive towards building a workplace free of racial prejudice and discrimination, and work to improve service delivery to a multicultural Britain. Many have seats on constabulary policy-making bodies and advise senior officers, either formally or informally, on issues of racism, community relations and ethnic diversity. They are often called upon to either evaluate or organise and run recruitment and training initiatives.

\section{Recruitment}

As mentioned previously, minority ethnic recruitment is intended to change constabularies into institutions that have a workforce representative of the UK's ethnically diverse population. While senior management no longer seem to question the validity of recruiting more minority ethnic officers and staff, minority ethnic officers themselves may have a different opinion (see Rowe 2004). Cashmore's (2002: 329-34) article argued that targeted minority ethnic 
recruitment is 'window dressing'. The minority ethnic officers he interviewed felt that not only do more black staff have no effect on the overall police culture, but that these recruits will not be 'cut from the same cloth' as those who did not need heavy marketing to attract them.

The first point may indeed be valid. For instance, two BPA officers we interviewed said the following in relation to other minority ethnic officers being hesitant to join the BPA:

\begin{abstract}
We have non-members, and I work with one who ... doesn't want to join but understands that her colour makes her different... And there are issues for her because she is seeing, she knows, that she's different but she is seen very much as one of the lads, again. And she actually exhibits all those stereotypical traits in order to make people feel comfortable with her. Even though when you sit and talk to her she has got such very strong views about it.

I mean they don't really want to acknowledge that they are different. I mean I've spoken to one person in particular and she's said that she joined the police force to be a police officer and she doesn't want to join a group that separates her from the others.
\end{abstract}

However, one could argue that the only way to combat this tendency to institutionalise minorities into the dominant white police culture is to recruit more minority ethnic officers and support the work of the BPA. Several people we interviewed felt very strongly that the days of minority ethnic officers having to blend into the white occupational culture were over. They felt that it is no longer a matter of being a police officer who happens to be a member of a minority ethnic group (Holdaway and Barron 1997: 47), but that one can now be a minority ethnic police officer:

\footnotetext{
I mean now ... you just haven't got to tuck yourself away and be part of the group, you can be who you are. And I think we've raised the awareness even for those non-members (of the BPA) as well that it's okay to be out there and say, like, 'yeah I'm a Black man and I know about Black issues and I do think that this is not fair...'. We have raised the awareness that people can be proud to be who they are (BPA officer).
}

(The BPA has) made us maybe more aware of things that are happening. Maybe you can, you can overlook certain things because individually things might happen and you might think 'Well, I'm alone, I'll just ignore it'. But as a member of the group you think 'Hey, that's not right, that shouldn't be going on'. And you might feel that probably you have to speak out then against certain things because you know you're not now just one. You're one of a group, you're one of many. There's a voice there that will back you up, you know (BPA officer)

Thus, the institutionalisation of minority ethnic officers that Cashmore (2002: 329-34) warned about may indeed be significantly compromised if minority ethnic staff feel they are safe through their strength in numbers (via increased recruitment) and the work of the BPA to retain a separate identity from their white colleagues.

That argument aside, many of our interviewees expressed favourable opinions about the government and senior management's focus on the targeted recruitment of minority ethnic people. This contrasts sharply with Cashmore's (2002: 330) claim that most minority ethnic officers find targeted initiatives useless or harmful: 
I personally think that by recruiting more, progressing more and retaining more (minority ethnic people), those three things ... will change the attitude and the behaviour. Now people say that behaviour can change easier than attitude, but I personally think that attitude can change as well. When you've got ... a more diverse force the better is going to be the attitude, which will lead to better behaviour and that's my philosophy. And I strongly believe that. That's why I'm trying to recruit more people from minority ethnics (BPA officer).

Yes there's problems, with help and support, you can overcome that problem and by learning from those that are within the group to see how they can overcome this problem, so ... don't think just because we see those problems in police forces that you don't want to join to help change it. The only way you can change something is by being part of it. You can't do anything from the outside (BPA officer).

Our interviewees did recognise, however, that some colleagues might believe that too much effort goes into specifically targeting minority ethnic recruits. Colleagues may suspect that if these potential minority ethnic officers have to be invited to join so directly they may not be the right kind of person for the job, as Cashmore's (2002: 331) interviewees also observed. BPA officers we interviewed felt this extra effort was justified however, as the decision to join a police force is not the same for a minority ethnic person as it is for a white person:

So you know, the decision to become a police officer for a black person is not necessarily a quick, easy decision as it might be for a white officer... I had to look at where I came from, why I wanted to do it for the first instance and again saw the negativity. Because there is negativity out there about public services, police in particular. You know, so it was a big decision to make...

\begin{abstract}
The police force has gone out there and said 'Right, target the young Asians to go and join the force', I've said 'It ain't gonna be that easy'. Because 99 per cent of those Asian youngsters will be dictated to by their parents. And if their elders don't want them to join, you ain't gonna get them to join. You need to be sort of talking to the elders and convincing them that there is a career to be made out of joining the police force and whatever else before they'll start encouraging their offspring. Because as far as Asian society is concerned, their views are you go into jobs such as accountancy, doctorates, lawyer, teachers and also the preconceived idea that anyone who's come from India has always regarded the police force over in India as being totally corrupt.
\end{abstract}

As these quotes demonstrate, people of minority ethnic origin may have significant barriers to overcome before a police career can even be considered. As such, any extra effort a recruitment drive can make to address these circumstances could be beneficial. This does not mean that the officers so recruited are less suited to a police career in some way, as Cashmore's paper would suggest, only that one overall recruitment approach is no longer appropriate in an ethnically diverse Britain.

Some of the recruitment drives aimed at minority ethnic people have involved special projects or initiatives. Not all of these ended up being successful, but our interviewees blamed this on poor project management, especially communication about the reasons for project organisation and timing, rather than on the goals of recruitment drives in general. These instances of failure in targeted minority ethnic recruitment relate to one of Cashmore's (2002: 331) criticisms, namely, that these kinds of projects will lower standards for the recruits in order to meet targets. Our interviewees did not feel this was the case: 


\begin{abstract}
I think it's not a negative thing to try and recruit these people in this way, it's negative in the sense that it wasn't communicated to members of staff. So all of a sudden (new) people are walking round the stations... And nobody wants to have anything to do with them. And they're all black. And then people kind of think, 'Oh here we go, yet another scheme for black people, they're lowering the standards'. You know, and so whenever black members of staff found out about it, they went absolutely mental and they're angry because yes, in principle they agree with it, but it's the way it's done. It's got to be managed, there's got to be structure (BPA officer).
\end{abstract}

Rather than improving the impression of police work for minority ethnic people, the mismanagement or misdirection of the programmes has worsened the situation and frustrated existing black staff. However, this has not turned BPA members against such programmes, as was apparently the case for Cashmore's interviewees, but encouraged many of them to be more directly involved in the targeted recruitment projects.

Instead of recruitment drives, Cashmore (2002: 337-9) argued that more radical action is required to start changing police forces in the way the Home Secretary has mandated. He believes some kind of 'affirmative action' is needed and proposed what he calls 'accelerated action'. This temporary scheme would fast-track minority ethnic officers into the higher ranks of the force, the way some officers with university degrees can progress now under the Accelerated Promotion Scheme for Graduates (APSG). This would mean many more minority ethnic people in the higher ranks of the force, which Cashmore felt would be an effective way of changing 'the character, composition and standing of the police service'. He envisions that candidates would be drawn from serving minority ethnic officers who have 'degrees or equivalent experience' (2002: 339). Although Cashmore does not see this scheme as positive discrimination, one wonders how it could be otherwise as there already exists a fast-track scheme for graduates in the police service, to which minority ethnic people are already eligible. To design a separate scheme specifically for minority ethnic people with 'degrees or equivalent experience' is surely knocking on the door of positive discrimination, if not just special treatment.

Regardless of whether or not Cashmore's promotion scheme is actually a case of positive discrimination, we found in our interviews with BPA members that minority ethnic officers despise initiatives like this. ${ }^{5}$ Our interviewees felt that they had a difficult enough time as it was gaining acceptance, let alone entering or progressing through the force on special terms:

We want our members to advance within the group, but advance fairly. Not be seen to be given favours. We don't want favours, we can work for it, and achieve it, and we have to work twice as hard to achieve it ... as a black person, because we have to prove not only you're better than this other person, but you know, you're working harder. 'Cause you yourself have to prove to him and you have to prove to community out there that you've achieved what you've achieved on your own, on your own merit (BPA officer).

We're saying, 'Get us to the starting line'. That's it. After that we jump through the hoops just like anybody. All our members will say 'I couldn't work for a black officer, Asian officer or any minority officer or any officer who was there just because of the colour of their skin. If they weren't competent, I couldn't do it...'. So really we've always thought that this isn't about creating jobs for black people, it isn't about pushing through or ahead of anybody in the promotion system. It's just about let's get to the starting line first and have a really good chance (BPA officer). 
Even Cashmore's respondents (2002: 338-9) seemed hesitant to adopt any sort of scheme that prioritised minority ethnic people over other officers in promotion systems. Our research has revealed that the BPA provides the kind of support network minority ethnic officers may need to face the challenges of getting ahead in the police. This suggests that increased constabulary support for the work of the BPA is the preferred approach to encouraging minority ethnic promotion opportunities.

However, this is not to suggest that the current recruitment schemes, be they positive action or just targeted recruiting, are perceived as adequate and sufficient. Many of our interviewees pointed out that, once the new minority ethnic recruits had begun their police work, they still faced unique issues. This is another area where groups like the BPA are vital. They can provide a muchneeded support base for minority ethnic officers finding their feet in a constabulary.

So if they said, 'Right, this is where we're going, this is the recommendation that came out of Stephen Lawrence. This is the target in terms of recruiting', which we're very good at, we are superb at recruiting. My question is what do we do with them when they come in? Nothing is the answer, absolutely nothing ... okay they've got the retention because they can say that the BPA will pick up people that are broken. And that's what we do, like l've said to you. We pick them up when we've got nowhere else to go. So sometimes we mentor, we work with them. We say 'Don't worry. We went through that. These are some of the strategies, and along with those strategies what we will also do is come and challenge on your behalf' (BPA officer).

We've made a difference in terms of retention and recruiting, because lots of people have come in, because we've got a BPA. I can talk to you about individuals that would have gone to other forces to get away from the hassle of the community, yeah, but because of the BPA, they've come, they've had a chat with us and they've thought 'Blimey and yeah we want to be part of this'. And they've joined and we've supported them (BPA officer).

We would argue that any assessment of recruitment and retention of minority ethnic officers and staff must include a consideration of the role played by BPAs, and this is where Cashmore's paper was weakened. BPAs are present in most police forces in the UK now and are becoming vital to Human Resource management strategies to ensure that any gains made towards meeting their recruitment targets are not lost after the initial years of service. Many BPAs provide informal or formal mentoring services and advise senior management on ways to retain minority ethnic staff. To omit a consideration of the role the group plays in these endeavours is to miss a vital aspect of the way police policy and practice are currently formed. Cashmore (2002) did not indicate whether he had contact with the BPA or any role it or other support groups may play in recruitment and training.

Despite this need for the BPA to help retain minority ethnic officers and police support staff and advise on force policy, many of the BPAs we interviewed felt that they are undervalued by their organisation.

So I ask the question...'Well, where do we fit in?' We don't fit in anywhere. We are a piecemeal organisation that picks up all the little bits and pieces round the edges. We don't get into the centre and if we do, it's at the last minute. And then we're not briefed because we're not privy to all the stuff. And then they'll make the policy and they 'Ooh,' as an 
afterthought 'Can we have the BPA to give their comments on this?' And it's like yesterday they want the comments, which you cannot do that on a professional basis.

I've said to Senior Management 'I am no longer prepared on my rest day to come and have meetings with you...'. Can you see what's the point that I'm trying to make? If they value us, they would make sure that we've got some facilities.

The problem is that when you have a group like this, they're quite keen to get you on the policy making meetings ... quite senior-level policy-making groups... However, when you've got people who've got day jobs and front-line officers and we're short on officers on the street, it's quite difficult to do that... So now, we go to meetings when we can, but it's not our top priority. You know, so we ourselves had to take a step back and think 'Oh we're just letting ourselves be used too much as a force tool'.

Our research suggests that, while targeted minority ethnic recruitment is important, what is equally if not more important is what happens to the officers after they are posted to a constabulary. Groups like the BPA have proven to be excellent resources for senior management to help achieve their recruitment targets and will often take it upon themselves to assist in the retention of these new minority ethnic officers. Some BPAs have established formal 'buddy' systems where each new minority ethnic recruit is paired with an existing minority ethnic officer who is willing to provide moral support and advice twenty-four hours a day. Senior officers often call upon BPA members for advice on recruitment and other matters, either in formal policy-making groups or informally. Several Assistant Chief Constables or Chief Constables have also made it clear that their door is always open to their BPA. However, if senior management is unwilling to provide the resources the BPA needs to undertake such work, they may start to follow the path of the last two BPAs quoted above and withdraw all but their support group activities. This is in turn will have an adverse effect on the vital recruitment drives and targets. ${ }^{6}$

\section{Training}

So far this paper has been concerned with the value of minority ethnic recruitment for police forces, as this formed the first half of Cashmore's (2002) critique of current police and government policy. The second half of his critique examined diversity training (or its equivalent) in police forces. Primarily, he explored the 'effectiveness, focus and philosophy' (2002: 335) of this training and generally found it lacking or misguided on all counts. We will explore each of these issues in turn in relation to our own research on Black Police Associations to compare their perspectives with the individuals Cashmore interviewed.

Before beginning this analysis, however, we would like to examine what 'diversity training' means. Cashmore acknowledged that the term was not always used in the forces he studied, and that some of his interviewees may have experienced 'racism awareness' training rather than 'diversity training' (2002: 334). He did not engage in a discussion about the various manifestations of this kind of training, however (2002: 329). We feel it is important to point out that, while the remits of racism awareness, community and race relations and diversity training may overlap (HMIC 2003: 13), there are important differences between them. The 1997 HMIC 'Winning the Race' report advocated community and race relations training in 'prejudice and discrimination' (among other topics) for all 
police officers (para 3.70). However, the follow-up report in 1999 only found sensitivity to symbols, places of worship, and other cultural issues in 'event' policing, such as religious festivals (HMIC 1999: para 5.1.14). HMIC advocates applying this knowledge as well as other training on racism to all day-to-day policing and to the work of support staff as well as uniformed officers (paras 5.1.13-14). In general, the follow-up report found that training in community and race relations issues was not consistent around the country and that a large part of training was directed at internal equal opportunities issues rather than external relations with the community, such as in the use of stop and search powers (paras 7.9.1-3). So we can see that while community and race relations training, similar to Cashmore's 'racism awareness' training, had good intentions, in practice it did little more than teach officers about the mechanics of various cultures and how to avoid internal race discrimination claims.

In more recent years, police forces have been implementing 'diversity training' instead of the traditional community and race relations training. The purpose here is to include training on issues related to more than just race and ethnicity, such as sexual orientation, disabilities, asylum-seekers, youth, the elderly, and other groups. Again the focus is on both internal relations and external service delivery (HMIC 2003: 60-4). However, the HMIC has urged that race-related issues still maintain the highest profile within this training in light of the Race Relations (Amendment) Act 2000 and its feeling that police forces have by no means 'solved' their racism problems (2003: 13, 61-2; Rowe 2004). Thus, the focus of all these various 'race' training methods has shifted from a rather shallow 'awareness' of other cultures to a deeper understanding and appreciation of all kinds of difference and how police work needs to respond to that. For simplicity's sake, we will refer in this paper to 'diversity training', as that was the type of training with which the majority of our respondents were involved and was the term Cashmore (2002) used. However, we note that this does imply a particular kind of training which in practice is not necessarily the same as 'race awareness' or 'community and race relations training', and consequently some of Cashmore's respondents may have experienced a kind of training that is no longer in place.

\section{Effectiveness}

In relation to effectiveness, Cashmore quoted two officers who felt diversity training has had no effect on police officers. They argued that it has been in place for almost twenty years now and that racism in the force has not changed in that time (2002: 335). Our research did not reflect this view wholly, however, as evidenced by the quotes below. Here, BPA officers reflect on their own involvement in diversity training, either in formal group sessions or with individual officers, and the effect it has had on their colleagues.

Middle managers tend to be seen as part of the problem by their lack of action. They weren't actually openly hostile... But they weren't ... showing the real leadership that was required ... until we started to show that you can show good leadership in race and equality just as how you can show good leadership in operational and general policing duties. So when you started to make that link ... how everyone should benefit from valuing your staff more, playing to their strengths not stigmatising their differences ... so middle managers has, again it's starting to filter through as these middle managers have passed on up the ranks or stayed (in) specialisms. 


\begin{abstract}
He (a white colleague) came back in here, and we sat down and we had about a good half an hour or so. Talked things through and notwithstanding that, he has now gone back into the work environment, very positive... From what his direct feedback to me, he understands the issues now. He feels as opposed to going to the work environment bitter and twisted, he's, and I think the term he uses, he feels he can now walk with his head up held high again, and you know, much more together. And that to me is good. 'Cause he can go back on his team, he likes his job, perform, and if the scenario came up again... I'm confident that individual would actually utilise that experience (and) make sure that that scenario doesn't happen again.
\end{abstract}

This is not to suggest, however, that our respondents felt that the existing diversity training was flawless. In fact, it was difficult to find any respondent who saw no room for improvement in his or her force's training programmes. The point is that, rather than scrapping the idea of training all together, as Cashmore and his interviewees seemed to suggest (2002: 334-5), a number of our respondents were optimistic about the potential for real behavioural change that exists in training and how their own involvement can help to achieve it. Below are quotes from respondents who have been involved in either delivering or assessing their force's training provisions and the plans they have for its future.

\begin{abstract}
Within the force one of the things that we've started, or has been started up nationally is what we've called our '-Training,' which is diversity and all that sort of thing encapsulated into one where everybody in the force goes away for this two-day course which touches on all those issues... And when I did my first course ... my experience was it was a nightmare? I fed all that back to the trainers... And you sort of said, well, 'Is two days really sufficient?' And the way we've looked at it is, well, it's two days that possibly would never have happened before and some people had never sort of had this frank type of discussion at all. All we can do is give the two days and then review and say 'Look, do we need to do further training? Is there still gaps in this? And what can we do about that?' So it's still being evaluated now as how we now progress onto the next stage of this.
\end{abstract}

If all staff understood themselves, then actually I would say they would be less likely to challenge others' diversity. You know, if they, if everyone buys into this 'I'm the same as X, Y and $Z$ '. And that person's different because of their colour or their gender or their sexuality, then we're always gonna have a problem. We don't, if we can help our staff to realise that each and every one is a unique individual with their own diversity and their own needs and expectations, requirements. Then actually, surely we're being about a service which is less intolerant.

So, while the current diversity training provisions are not perfect, BPAs are closely involved in assessing and improving them, and have many ideas for the future. It is clear that they do see a need for diversity training, in whatever form it may take. One needs to consider BPAs and their impact in any analysis of police training, as they are becoming key players in it. However, many BPAs are still young and only just securing this kind of influence. It may be a few years yet before the full extent of their impact can be felt.

\title{
Focus
}

Cashmore's second critique of police diversity training was that its focus is misguided. His respondents felt that it was too externally focused (and so did not look at racism within the police force with colleagues), patronising (in that it just made people aware of other cultures) and needed to be directed at senior officers 
as well as more junior officers (2002: 335). This is another example of where consideration of the role of the BPA in training adds much to the analysis of the first two points. Our respondents revealed how, through their own involvement in training, discussions could focus on the effects of racism on police colleagues and on much more accurate and grounded information about what it is like to be different from the majority. Through speaking about the role of the BPA in these training sessions, colleagues learn about why it was founded and its objectivesnone of which involve subverting the organisation (as many mistakenly believe), but rather to further the diversity work of the police (in training, recruitment, service delivery, etc.) and to support colleagues who experience racism.

\begin{abstract}
He said 'Would you mind coming in to a diversity course to talk about the BPA and what the benefits are for minority ethnic groups?'. So I agreed to that, went down and spoke about the BPA and the session went really well. People asked me lots of questions (such as) 'Had I had any discrimination?'... I spoke about the Asian communities and I said, you know, 'There are issues out there...'. And we took a session where, you know, it just took off really and we were asked about 'Well, I can't tell the difference between the Asians, you know. Because all of them have these turbans. What is that all about?'. And basically we were very brief about Sikhs in terms of, you know, they have got to have a turban and it is part of a religious uniform... That went down very, very well so he invited me in again. Went in again, had a good session and we thought it was very positive... (BPA officer).
\end{abstract}

It is quite $a$, it is a training session but it is quite interactive really in terms of, I mean my role is basically going in, raising awareness of the BPA, getting people thinking and to create a sort of like learning environment. Sometimes people say things and I am sure people go away ... and start thinking about some of the things I have said... Sometimes you will have some people who never went to cultural awareness, right, quite often people have spent a long while working. They have never, ever had any cultural awareness since they joined twenty odd years ago. And I think they benefit from it (BPA officer).

Several BPA members also discussed their own personal experiences of racism and felt this helps to bring home the message about valuing others as individuals, not as groups of people who happen to share certain characteristics. Thus much diversity training is not about learning the mechanics of other cultures, as 'community and race relations' training often was, but about appreciating everyone as an individual.

\footnotetext{
We were one of the first forces I think to have a formalised race awareness training course and our approach then was to say 'Look, the impact of the training was negligible...'. So we decided that we should try and utilise the black staff members who are willing to participate in the process as a vehicle for actually making them think and realise what that actually means. It's much more impactive to start and be saying, well, 'You've known me for five years, ten years, whatever. This is how I feel, this is my experience'. Not in ... some distant place, but within (your) police. So, the BPA's role within the training has been significant (BPA officer).
}

I go in and try to stimulate debate and I try to get people to open up their feelings... And talk about issues that perhaps affected some people like myself and when I joined, talk about some of the barriers I came up against when I joined in terms of how family and friends were actually discouraging me from joining... Some people you have to treat them a little bit differently than you would treat other people. So within policing it has always been, they have always gone down the line of treat everybody the same, treat everybody equal. And now people are sort of thinking about treating people according to their needs (BPA officer). 
Cashmore's third critique under 'focus' of diversity training was that it is not directed at senior officers (2002: 335). We found several forces where this is most definitely not the case. The extent of the training offered to the senior members of the organisation will vary from force to force, but they are not all being ignored. For example:

\begin{abstract}
We will actually, one of the proposals that we made to ... the Chief Constable in February was that the BPA run a workshop for Chief Officers, all of the Assistant Chief Constables and himself and other Senior Officers and to look specifically at race issues ... (and) he agreed with us. And he even offered to fund it ... and suggested where we should have it, which is the place where they have all their high level, you know, any kind of Chief Officers' meeting, which is off site.
\end{abstract}

The programme has been ongoing for about eighteen months. It started off with Senior Officers, i.e. above Inspectors, so the Chief Inspectors and above, right to the top. And they went on a three-day course... The -Programme was targeted at Support Staff Managers, Inspectors, Sergeants and Police Officers and that was a two-day.

Again, this is not to suggest that all senior officers are getting diversity training or that this training is always a huge success. However, our research demonstrates that much of the training that is being delivered is more focused and effective than Cashmore's (2002) paper argued, due in large part to the involvement of the local BPA.

\title{
Philosophy
}

Cashmore's final critique about diversity training was that its philosophy is questionable. His respondents were not sure if diversity training is meant to reform the whole person (attitudes about racism as well as behaviour) or just change behaviour alone. Many of them seemed to feel that it was failing in either case and that training can never do what senior managers hope it will (Cashmore 2002: 336-7). Only one seemed to suggest that just changing behaviour was acceptable. This debate around changing behaviour alone versus changing attitudes and behaviour was a recurring theme in our interviews, with both BPA members and senior officers. ${ }^{7}$ The BPA members were by no means in agreement over the issue. Some mirrored the comments made in Cashmore's paper, in that changing racist attitudes is important but that current diversity training will not be able to achieve it:

To actually change the direction of the organisation, you have to somehow change the direction of its component parts. Not just the policies, it's great you know, you can have a wonderful policy. But it's on the wall and, you know, say 'Ooh! Tick that box, we've got this wonderful policy'. But if you don't actually address the individuals who have to implement the policy ... address their attitudes and behaviour ... then you know, you're not going to get down to the root of the problem. Which is why I think a two-day CRR training is a bit of a tick-box exercise, because you don't address anybody's real attitude of [OR?] behaviour ... in two days. But you can tick the box that says that you've done it (BPA officer).

It is difficult to change a person's views. I mean, those are intrinsic to an individual, so it's difficult to change those views. If you are brought up with certain beliefs then exposure to a training course is very unlikely to change them massively (BPA officer). 
Many of our respondents, however, took a different approach. While they agreed that changing attitudes would be preferable, they realised that it would not always be possible and so were willing to settle for a change in officers' behaviour instead:

\begin{abstract}
I mean, if people want to be racist then so be it, but it's just, I think you need ... the only thing you can ask for is for people to be ... to have a neutral value at work... 'Cause if people want to be complete and utter sort of, like Nazis or racists, in their home lives, then so be it...You can't be the thought police can you? It's just like keeping a neutrality at work. That's the only thing you can [DO?] ... 'cause you can't stop freedom of thinking... It doesn't matter if you're prejudiced against people really, does it? As long as you don't discriminate against them by treating them differently (BPA officer).
\end{abstract}

If we can just change behaviour that should be enough. Because the bottom line is that people will always believe what they believe, but if you can change their behaviour in the workplace then I think we have to settle for that really. And that's what we aim to do, you know, to try and educate them that what they got away with ten years ago is just not acceptable. So some have turned around and I can think of a couple that have had to work with us because of one reason or another and it's just opened their eyes (BPA officer).

Many senior officers have taken a 'zero tolerance' approach when it comes to racist behaviour or comments from their employees. All officers now know that if they are caught doing or saying anything that can be construed as racist, they could lose their jobs. Many of our respondents feel that this, coupled with the diversity training, is the next best thing to actually changing racist attitudes. As long as there are no outward signs of prejudice, then that is the best one can hope to achieve. So, unlike in Cashmore's research, our respondents generally do see a role for diversity training in addressing racism within the police and wish it to continue.

\title{
Conclusion
}

This paper has demonstrated that any discussion of police minority ethnic recruitment or diversity training needs to consider the role the local Black Police Association has in these endeavours. Since the publication of the Macpherson report, police forces have been under unprecedented pressure to achieve certain levels of minority ethnic recruitment and to improve their diversity training demonstrably. The Morris Inquiry (Metropolitan Police Authority 2004) into the disproportionate use of disciplinary investigations against minority ethnic officers in the Metropolitan Police shows that still more needs to be done. The HMIC has identified BPAs as indicators of good practice and as useful resources for senior officers in achieving these goals. BPA members are the minority ethnic officers with the ear of senior management and are the ones most likely to influence policy and practice. It is understandable that Cashmore's (2002) study did not include a mention of the BPA if he was interviewing non-members (although he does not indicate if this is the case or not). For them the BPA may not have much relevance. For senior officers and for current BPA members (especially members of the executive committee, such as chairs and deputy chairs) it most certainly does have relevance, however. BPA members are the first minority ethnic staff to be approached by senior management when they need advice in areas of minority ethnic recruitment and diversity issues, as this is a self-declared group of 
people who have stated, in writing via their constitution, that they are open to such approaches. Senior officers would be very unwilling to approach a non-BPA member for such consultation for fear of offending the person by bringing his or her ethnicity to ascendance. The BPA, by its very existence, does this already and so gives the green light to these kinds of consultations. Therefore their knowledge of, and influence in, policy and practice is much greater than that of non-BPA members.

This touches on another key point about the effect of BPAs in their forces. As mentioned above, BPAs by their very nature put the ethnicity of their members to the fore. This has had an impact on the way minority ethnic officers identify themselves in the workplace. Previous research (Holdaway and Barron 1997) found that most minority ethnic officers preferred to see themselves as 'police officers who happen to be black'. Our work here suggests this has changed and it is now acceptable for one to identify oneself as a 'black police officer', and to take pride in one's difference from the majority. This could potentially have important effects on the wider police culture with distinct variations now gaining acceptance. Perhaps new police cultures based on similar variations, as espoused by the BPA, could develop a significant presence and allow minority officers to not feel they must 'blend in' by 'acting white' with their colleagues. This is a point on which we will conduct further research.

The purpose of the paper was not to evaluate the effectiveness of minority ethnic recruitment and diversity training, but to compare the views of our respondents on these topics to those of Cashmore's interviewees (2002). If we were to briefly comment on these initiatives, however, it would be to say that while recruitment and training do show some scope for addressing issues of diversity in their institutions, they should not be seen as the only two answers to the problem. These initiatives need to be part of a broader plan for organisational change (Holdaway 1996: 125; Rowe and Garland 2003), one that sees an awareness of diversity in all aspects of police work, not just in recruitment and training, and an acknowledgement that the police culture will take a much longer and more systematic effort to change. As we have demonstrated here, we feel BPAs will play a large role in that long-term effort. Many of our respondents mentioned that change in the police is always a slow process and so one needs to be patient for results from current work.

\section{Notes}

[1] 'Diversity training' is the current term for what has in the past fallen under different titles and manifestations, such as 'racism awareness' or 'race and community relations' training for police officers and civilian staff. The term 'diversity training' is the one used most often in our interviews and is the one Cashmore (2002) used.

[2] The research was funded by a grant from the Economic and Social Research Council, award number R000239360. It ran from October 2001 to September 2003.

[3] As this paper is based on qualitative research, we do not have exact numbers of how many of our respondents felt positively or negatively about minority ethnic recruitment and diversity training. Certainly not all of our respondents felt that these programmes were perfect nor an end in 
themselves. Some see them as starting points from which to base other endeavours to make the police force a more diverse and ethnically harmonious employer. In addition, the exact nature of these programmes will vary around the country, as will the level of involvement each local BPA has in them. However, we feel the quotes we have included here are fairly representative of the content of our interviews and give a general impression of the opinions expressed to us.

[4] During the time of Scarman's report minority ethnic police officers comprised 0.3 per cent of serving officers nationally (Scarman 1981: 122), and were 1.45 per cent of serving police officers in 1993 (Holdaway 1996: 141). Considering minority ethnic people comprised 5.9 per cent of the population in England and Wales in the 1991 census, this is not an adequate improvement to make the police force more representative of the community it serves.

[5] However, the National Black Police Association recently called for quotas to be established to increase the number of minority ethnic police officers in all ranks. They feel it is the only way to meet the recruitment targets the Home Office set after the Macpherson Inquiry (BBC News: 4 September 2004). This is in direct contrast to the views of the constabulary BPA officers we interviewed, who strongly opposed any form of affirmative action.

[6] Such as when the National Black Police Association urged black and Asian officers to boycott minority ethnic recruitment drives in the Metropolitan Police in protest over the collapsed talks to reinstate Supt Ali Dizaei (BBC News: 8 October 2003). Supt. Dizaei had been suspended due to several internal investigations, which were all eventually either dropped or proved unfounded.

[7] It has also been a recurring debate in police training departments; see Rowe and Garland (2003: 401-3).

\section{References}

BBC News (2003) 'Met faces black police boycott', BBC News online, http://news.bbc.co.uk/1/hi/uk/3173200.stm, 8 October 2003.

BBC News (2004) 'Quotas call by black police group', BBC News online, http://news.bbc.co.uk/1/hi/uk/3626788.stm, 4 September 2004.

Cashmore, E. (2002) 'Behind the window dressing: minority ethnic police perspectives on cultural diversity', Journal of Ethnic and Migration Studies, 28(2): 327-41.

Goodson, A. (1984) 'Police and the public', in Benyon, J. (ed.) Scarman and After: Essays Reflecting on Lord Scarman's Report, the Riots and their Aftermath. Oxford: Pergamon Press, 143-51.

Griffiths, B. (1984) 'One-tier policing', in Benyon, J. (ed.) Scarman and After: Essays Reflecting on Lord Scarman's Report, the Riots and their Aftermath. Oxford: Pergamon Press, 125-34.

Her Majesty's Inspectorate of Constabulary (1997) Winning the Race: Policing Plural Communities. London: HMSO.

Her Majesty's Inspectorate of Constabulary (1999) Winning the Race: Policing Plural Communities Revisited. London: HMSO. 
Her Majesty's Inspectorate of Constabulary (2001) Winning the Race: Embracing Diversity. London: HMSO.

Her Majesty's Inspectorate of Constabulary (2003) Diversity Matters. London: Home Office Communication Directorate.

Holdaway, S. (1996) The Racialisation of British Policing. Houndmills: Macmillan.

Holdaway, S. and Barron, A. (1997) Resigners? The Experience of Black and Asian Police Officers. Houndmills: Macmillan.

Holdaway, S. and O'Neill, M. (2004) 'The development of Black Police Associations: changing articulations of race within the police', British Journal of Criminology, 44(6): 854-65.

Loveday, B. (2000) 'Must do better: the state of police race relations', in Marlow, A. and Loveday, B. (eds) After Macpherson: Policing after the Stephen Lawrence Inquiry. Lyme Regis: Russell House Publishing, 15-28.

Macpherson, Lord (1999) The Stephen Lawrence Inquiry. London: HMSO, Cm 4262-I.

Metropolitan Police Authority (2004) The Case for Change: People in the Metropolitan Police Service. The Report of the Morris Inquiry. London: The Morris Inquiry.

O'Byrne, M. (2000) 'Can Macpherson succeed where Scarman failed?', in Marlow, A. and Loveday, B. (eds) After Macpherson: Policing after the Stephen Lawrence Inquiry. Lyme Regis: Russell House Publishing, 107-12.

Rowe, M. (2004) Policing, Race and Racism. TOWN OF PUBLICATION? : Willan Publishing.

Rowe, M. and Garland, J. (2003) "Have you been diversified yet?" Developments in police community and race relations training in England and Wales', Policing and Society, 13(4): 399-411.

Scarman, Lord (1981) The Brixton Disorders 10-12 April 1981. London: HMSO, Cm 8427. 